\title{
Legally Interred and Unlawful Burials: A Retrospective Study of Exhuma- tion Cases in the Province of Quebec, Canada
}

\author{
Célia Kremer and Anny Sauvageau*
}

Laboratoire de sciences judiciaires et de medicine légale, Montreal, Canada

\begin{abstract}
Exhumations cases have been the focus of very few retrospective studies. In fact, no study ever described unlawful burials, while exhumations of legally interred bodies were only described by German studies. In the present study, exhumation cases of legally interred and unlawful burials performed over a six-year period (2000-2005) in the province of Quebec, Canada, were retrospectively analyzed. A total of 8 cases were found, representing $0.2 \%$ of all forensic autopsies and $0,0024 \%$ of all deaths. Of those, 5 were unlawful burials $(62.5 \%)$, whereas the remaining $3(37.5 \%)$ were legally interred bodies. Overall, the time of interment ranged from 2 weeks to 2 years. Forensic pathologists participated in 5 of the $8(62.5 \%)$ exhumation cases. Exhumations rates in different populations are discussed, as well as reasons to conduct an exhumation and if the forensic pathologist must be present on the scene.
\end{abstract}

\section{INTRODUCTION}

Exhumation, also called disinterment or disentombment, refers to the uncovering, digging up or removal of a body from a grave, although those terms can be loosely applied to describe the removal of a body from any tomb below or above ground [1]. Exhumations performed by forensic anthropologists/pathologists occur in two general contexts: legally interred bodies and unlawful burials [2,3]. Legally interred bodies are burials which have been approved by the authorities and which are buried in a cemetery. Unlawful burials on the other hand involve bodies not found buried in a cemetery and are the result of an individual or group trying to conceal or dispose of a body. Some authors further divide the exhumations of legally interred bodies in two categories: civil cases and criminal cases [3,4]. Exhumations for civil purposes are done to determine if the deceased medical diagnosis or treatment was faulty, if a pre-existing illness affected life expectancy, if conscious pain and suffering was present and for how long, if drugs or alcohol contributed to an accident, if an injury was caused by faulty appliance and so forth $[3,4]$. Criminal cases, on the other hand, are done to establish if the cause of death is related to a criminal act, often in the context of new information following the interment.

Very few studies have been conducted to retrospectively analyze exhumation cases. In fact, apart from German studies [5-9], the forensic literature lacks a systematic review of such cases. Furthermore, as far as we know, retrospective studies of exhumation cases focused only on legally interred bodies, without describing cases of unlawful burials. Here presented is a 6-year retrospective study of all cases of exhumation conducted in the Province of Quebec (Canada).

\footnotetext{
*Address correspondence to this author at the Laboratoire de sciences judiciaires et de médecine légale, Édifice Wilfrid-Derome, 1701, Parthenais street, 12 ${ }^{\text {th }}$ floor, Montreal (Quebec) H2K 3S7, Canada; Tel: (514) 8733300; Fax: (514) 873-4847; E-mail: a.sauvageau@ @sp.gouv.qc.ca
}

\section{MATERIAL AND METHODS}

All cases of exhumations performed over a 6-year-period (2000-2005) in the province of Quebec, Canada, were retrospectively studied. Exhumation cases of legally and unlawful burials were both selected. In order to be considered in the present study, cases of unlawful burials had to present at least some element of interment - even minor, such as a body covered at least by a few inches of soil or stones. For each case, the following elements were analysed: gender, age, time of interment and presence or not of a forensic pathologist on the exhumation site.

\section{RESULTS}

A total of 8 exhumations were performed in the province of Quebec from the years 2000-2005 (Table 1). This represents $0.2 \%$ of all forensic autopsy cases within the 6-year study period. Of the 8 exhumations, 3 were legally interred bodies, which represent $37.5 \%$ of exhumation cases and $0.07 \%$ of all autopsy cases. The remaining 5 cases were unlawful burials, representing $62.5 \%$ of exhumation cases and $0.12 \%$ of all autopsy cases. The time of interment for legally interred bodies ranged from 2 weeks to 2 years, whereas for unlawful burials, the range was from 2 weeks to 1 year. Overall, forensic pathologists participated in 5 of the 8 $(62.5 \%)$ exhumation cases. A forensic pathologist was called to the cemetery for 2 of the $3(66.6 \%)$ legally interred exhumation cases, whereas for unlawful burials, a forensic pathologist was present in 3 of the 5 cases $(60.0 \%)$.

\section{DISCUSSION}

\section{Exhumation Rates}

The exhumation rate in Quebec, Canada, between 2000 and 2005 was of $0.2 \%$ of all forensic autopsy cases. Most exhumations were of the unlawful burial type, representing $62.5 \%$ of cases, with a corresponding rate of $0.12 \%$ of all autopsy cases. Legally interred bodies were performed with a rate of $0.07 \%$ of all autopsy cases. In the literature, there is no comparative rate for exhumations of unlawful burial type. 
Table 1. Exhumation Cases from 2000 to 2005 in Quebec, Canada

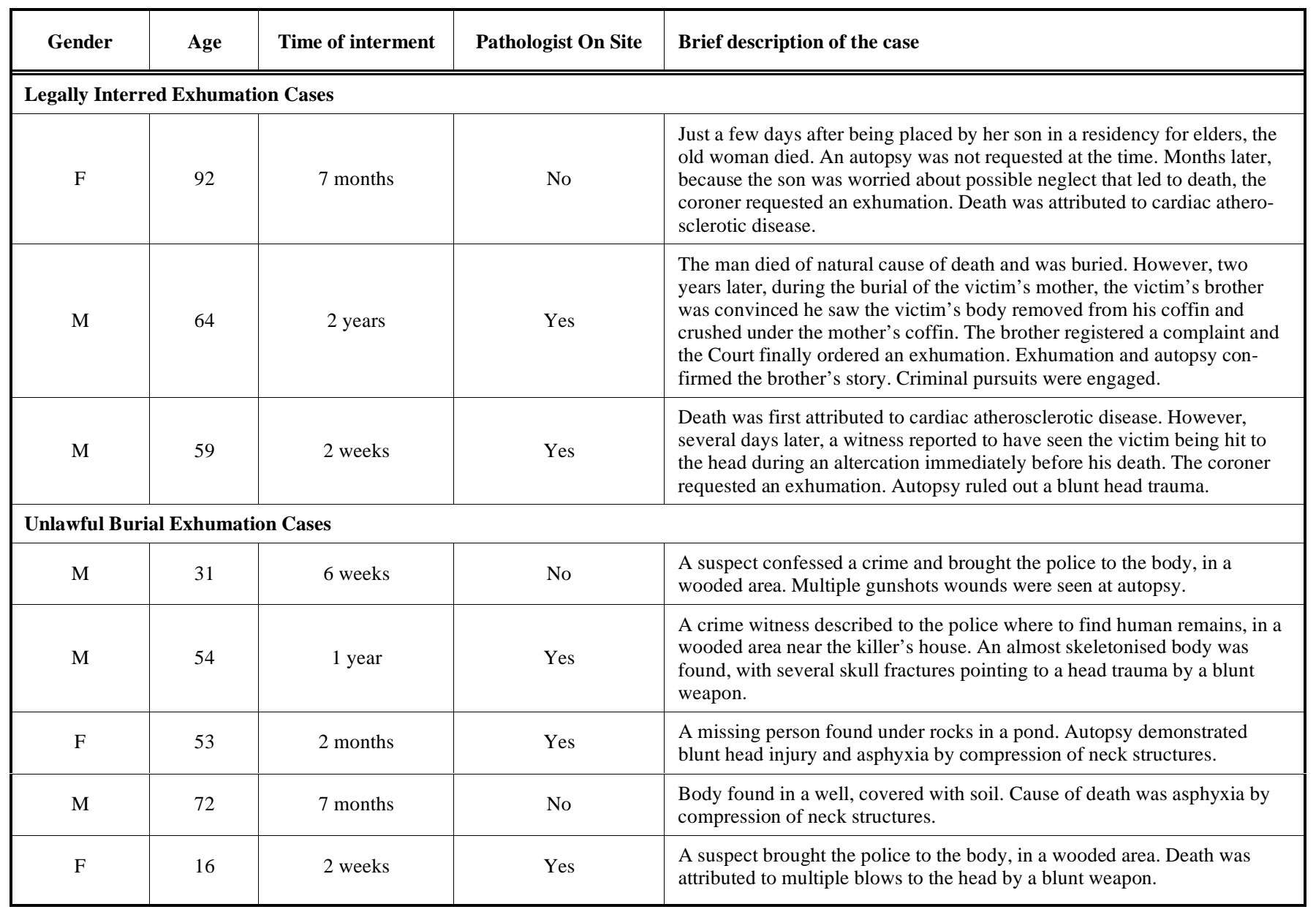

Comparative data are available, on the other hand, for exhumation rates of legally interred bodies. In Rio de Janeiro, Brazil, the exhumation rate was reported to be around $0.28 \%$ of all autopsy cases [10]. In Hannover and Cologne, Germany, $0.64 \%$ and $1.36 \%$ of all autopsy cases were respectively exhumed in two 20-year studies [5,7]. In a study from 1967 to 2001 in Münster, Germany, the exhumation rate reached 1.2 to $1.4 \%$ [6]. Therefore, the exhumation rate in Quebec is significantly smaller than in Germany and Brazil. In fact, our exhumation rate of $0.07 \%$ is closer to the $0.06 \%$ exhumation rate in Saint-Petersbourg, Russia [11].

The discrepancy between our exhumation rate and the exhumation rates in Germany may be explained by the principle of reciprocity proposed by Brinkmann: exhumation rates are inversely correlated with the autopsy rates [12]. Following this hypothesis, regions with high autopsy rates are associated with lower exhumation rates and vice-versa. As a matter of fact, the province of Quebec, Canada, has an autopsy rate of $3.1 \%$ of all fatalities, compared to 1.2 to $1.4 \%$ in Münster, Germany [6]. Therefore, it is not surprising that the exhumation rate in Quebec represents $0.0024 \%$ of all deaths, compared to $0.016 \%$ in Münster.

It is also highly interesting to note that in Quebec, the exhumation rate of unlawful burial exhumation cases was 5 times higher than for legally interred exhumation cases. It would be interesting that further studies could be conducted in different areas to compare this data.

\section{Gender and Age}

In the German literature, 3 retrospective studies of legally interred exhumation cases all revealed a male predominance, ranging from 62 to $74 \%$ of cases [5-7]. This is in keeping with our male:female ratio of 2:1 for the legally interred cases. As for the unlawful burial cases, there is no previous studies on the male:female ratio. According to the present study, a male predominance is seen in those cases as well. However, considering the small number of exhumations in Quebec during the study period, further research is necessary to confirm this male predominance in unlawful burial.

Age of legally interred cases ranges from birth to over 90 years of age [5-7]. However, the average age is generally around 55-years-old, with the majority of cases over 50 [57]. This predominance of older victims in exhumations of legally interred cases was also observed in the present study. Unlawful burial cases were not previously studied as to their age range. According to our results, they seem to be younger than legally interred cases, with an average age of 45 . It would be interesting to study this age disparity in other populations as well.

\section{Time of Interment}

In this study, time of interment for unlawful burial exhumation cases was about the same as for legally interred ones, ranging from 2 weeks to 1 year and 2 weeks to 2 years 
respectively. Once again, for unlawful burial exhumation cases, no comparative data was found in the literature. As for legally interred cases, German studies have reported time of interment varying from 5 days to 20.5 years [5-8]. However, the large majority of exhumations were performed within a year after interment [5-6]. This is in keeping with the results in our case series.

\section{Reasons to Conduct an Exhumation}

For unlawful burial exhumations cases, reasons to conduct the exhumation are obvious: to find the identity of the deceased as well as to establish the cause and manner of death. Most of those cases consist of homicides.

In legally interred bodies, exhumations are commonly conducted to retrieve bodies or body samples for analysis to solve specific questions relating to events during life or death of the exhumed individual [13]. The objectives of disinterments are therefore to uncover previously undocumented evidence that, for some reason, had not been retrieved before burial [4]. Success depends on the questions to be answered as well as the condition of the body [5]. Karger et al. identified 5 main indications for exhumation: 1) primary suspicion of intoxication, 2) primary suspicion of homicide, 3) possible medical malpractice, 4) accidents including traffic accidents and 5) clarification of cause of death, circumstances or identity [6]. According to their retrospective study of 155 exhumations over more than 30 years, the most common indication is primary suspicion of homicide (51 cases out of 155), followed by possible malpractice (39 cases) and accidents including traffic accidents (30 cases). In another German retrospective study, main indications for exhumations in 46 cases over a 20 -years period were problems of causality in social and civil law (14 cases), suspected intoxication (10 cases), possible medical malpractice ( 7 cases) and criminal aspects of traffic accidents (7 cases). This rather strong proportion of exhumations for questions concerning criminal aspects of traffic accidents may partly explain the higher exhumation rates in Germany compared to ours. As a matter of fact, traffic accidents in Quebec are all under a no-fault provincial insurance, so there is less pressure for investigating possible criminal aspects of traffic accidents (apart from hit-and-run and impaired driving). Therefore, apart from the reciprocity principle between autopsy and exhumation rates previously mentioned, another source of discrepancy in the exhumation rates from one area to the other could be differences in legislations.

\section{Presence of the Forensic Pathologist on the Exhumation Scene}

In Quebec, for the 2000-2005 period, a forensic pathologist was present on the exhumation site for most cemetery as well as unlawful burials exhumations. Whether or not the presence of a forensic pathologist or anthropologist is mandatory on all exhumation sites is open to discussion.
For legally interred bodies, Hanzlick stated, in an interesting review paper, that whether the pathologist needs to be present or not depends on the needs of the case and the condition of the gravesite, and that decision requires judgment by the pathologist [1]. He further discussed that in general, if there is no question as to the location of the grave, vault, casket (and body), or identity of the deceased, if toxicology is not relevant to the case, and if there is good reason to believe that the vault and casket are intact, there is probably little or no need for the pathologist to attend the disinterment.

For unlawful burials however, the presence of a forensic pathologist or anthropologist is highly important and could change the final outcome of a case. Indeed, the presence of a forensic expert could protect against inappropriate disinterment techniques or loss of evidence. This is in keeping with Menez, who emphasized that it is useful to request a medical examiner or pathologist to come to the scene, as seeing the body in context might aid in the resolution of a case or in establishing a cause and manner of death [14].

\section{REFERENCES}

[1] Hanzlick, R. Embalming, body preparation, burial, and disinterment. An overview for forensic pathologists. Am. J. Forensic Med. Pathol., 1994, 15, 122-31.

[2] Vanezis, P.; Sims, B.G.; Grant, J.H. Medical and scientific investigations of an exhumation in unhallowed ground. Med. Sci. Law, 1978, 18, 209-21.

[3] Baden, M.M. Part 4. Exhumation - Time of death and changes after death. In: Spitz, W.U., ed. Spitz and Fisher's medicolegal investigation of death: guidelines for the application of pathology to crime investigation. $4^{\text {th }}$ edition. Springfield, IL:Charles C Thomas Publisher LTD, 2006, 174-83.

[4] Eckert, W.G.; Katchis, G.S.; James, S. Disinterments. Their value and associated problems. Am. J. Forensic Med. Pathol., 1990, 11, 9-16.

[5] Breitmeier, D.; Graefe-Kirci, U.; Albrecht, K.; Weber, M.; Tröger, H.D.; Kleemann, W.J. Evaluation of the correlation between time corpses spent in in-ground graves and findings at exhumation. Forensic Sci. Int., 2005, 154, 218-23.

[6] Karger, B.; Lorin de la Grandmaison, G.; Bajanowski, T.; Brinkmann, B. Analysis of 155 consecutive forensic exhumations with emphasis on undetected homicides. Int. J. Legal Med., 2004, 118, 90-4.

[7] Grellner, W.; Glenewinkel, F. Exhumations: synopsis of morphological and toxicological findings in relation to the postmortem interval. Survey on a 20year period and review of the literature. Forensic Sci. Int., 1997, 90, 139-59.

[8] Stachetzki, U.; Verhoff, M.A.; Ulm, K.; Müller, K.M. Morphologische Befunde und versicherungsmedizinische Aspekte bei 371 Exhumierungen. Pathologe 2001, 22, 252-8.

[9] Seibel, O.; Heinemann, A.; Hildebrand, E.; Püschel, K. 131 Hamburger Exhumierungen und ihre Bedeutung für die Rechtspflege und Versicherungsmedizin (1971-1995). Versicherungsmed, 1997, 49, 209-15.

[10] de Oliveira, S.F.; de Almeida, C.A.; da Silva Dalcin, B.L.; Koch, H.A.; Gutfilen, B. Importance of radiological diagnosis applied to necroscopy. Forensic Sci. Int., 2006, 158, 173-6.

[11] Loban, I.E.; Kurganova, I.V. Participation of a Forensic Medical Expert in Inquests. http://www.medline.ru/monograf/sudmed/a2/ 5tsast-11.shtml.

[12] Brinkmann, B.; Madea, B.; Wuermeling, H.B. Exhumierungen aus strafprozessualen Anlässen. Arch. Kriminol., 1986, 177, 65-75.

[13] Spennemann, D.H.; Franke B. Archaeological techniques for exhumations: a unique data source for crime scene investigations. Forensic Sci. Int., 1995, $74,5-15$.

[14] Menez, L.L. The place of a forensic archaeologist at a crime scene involving a buried body. Forensic Sci. Int., 2005, 152, 311-5. 